\title{
BMJ Open Reasons to stop drinking alcohol among patients with rheumatoid arthritis in Sweden: a mixed-methods study
}

\author{
Ingrid Larsson,, ${ }^{1,2}$ Maria L E Andersson,, ${ }^{2,3}$ For the BARFOT study group
}

To cite: Larsson I, Andersson MLE, For the BARFOT study group. Reasons to stop drinking alcohol among patients with rheumatoid arthritis in Sweden: a mixedmethods study. BMJ Open 2018;8:e024367. doi:10.1136/ bmjopen-2018-024367

- Prepublication history for this paper is available online. To view these files, please visit the journal online (http://dx.doi. org/10.1136/bmjopen-2018024367).

Received 23 May 2018 Revised 22 0ctober 2018 Accepted 7 November 2018

Check for updates

(C) Author(s) (or their employer(s)) 2018. Re-use permitted under CC BY-NC. No commercial re-use. See rights and permissions. Published by BMJ.

${ }^{1}$ School of Health and Welfare, Halmstad University, Halmstad, Sweden

${ }^{2}$ Spenshult Research and Development Center, Spenshult, Halmstad, Sweden

${ }^{3}$ Department of Clinical

Sciences, Section of

Rheumatology, Lund University, Lund, Sweden

Correspondence to

Dr Ingrid Larsson;

ingrid.larsson@hh.se

\section{ABSTRACT}

Objectives The aims were to identify patients with rheumatoid arthritis (RA) who had stopped drinking alcohol and compare them with patients drinking alcohol, and to explore reasons for stopping drinking alcohol.

Design A sequential explanatory mixed methods design was used.

Setting Six rheumatology clinics in Southern Sweden Better Anti-Rheumatic Farmac0Therapy cohort.

Participants A total of 1509 patients completed the questions about alcohol and were included in the study. 86 of these had stopped drinking alcohol and 72 responded to the open question and their answers were analysed with qualitative content analysis.

Outcome measures The quantitative data were from a cross-sectional survey assessing disease severity, physical function (Health Assessment Questionnaire, HAQ) and health-related quality of life (EuroQol five dimensions, EQ5D), pain, fatigue, patient global assessment (PatGA) and lifestyle factors, for example, alcohol. The questions assessing alcohol included an open question 'Why have you stopped drinking alcohol?'

Results The patients who stopped drinking alcohol were older (median (min-max) 69 (36-90) vs 66 (23-95), $\mathrm{p}=0.011)$, had worse HAQ (1.00 (0-2.75) vs 0.50 $(0-3.00), p<0.001)$, worse EQ5D $(0.69(-0.02-1.00)$ vs $0.76(-0.58-1.00), \mathrm{p}<0.001)$ worse PatGA $(5(0-10)$ vs $3(0-10), p<0.001)$, more pain $(5(0-10)$ vs $3(0-10)$, $p<0.001)$ and more fatigue $(6(0-10)$ vs $4(0-10), p<0.001$ compared with patients drinking alcohol. The qualitative content analysis revealed five categories describing reasons for patients with RA to stop drinking alcohol: illness and treatment; health and well-being; work and family; faith and belief; and dependences and abuse. Conclusions The patients who had stopped drinking had worse physical functioning and higher levels in painrelated variables. Most stopped drinking due to their illness or a desire to improve health.

\section{INTRODUCTION}

Rheumatoid arthritis (RA) is a long-term autoimmune disease, characterised by autoantibodies, synovitis, systemic inflammation, pain and disability, ${ }^{1}$ with a prevalence of $0.5 \%-$ $1.0 \%$ and an annual incidence of 25-50 per $100000 .^{2-4}$ The associations between RA and comorbidities, such as cardiovascular diseases (CVD), malignancies and chronic obstructive

\section{Strengths and limitations of this study}

To our best knowledge, no previous studies have aimed at exploring reasons for patients with rheumatoid arthritis to stop drinking alcohol.

- Methodology, a sequential explanatory mixed methods allowed a qualitative method to develop a more comprehensive understanding of the initial quantitative results.

- A multicentre study with participants from six rheumatology clinics in Southern Sweden Better AntiRheumatic FarmacOTherapy cohort.

- All measures were self-reported. Recall bias may thus have influenced the results.

- There was no opportunity to ask follow-up questions to the written responses in order to gain an even greater in-depth understanding while on the other hand written responses can allow patients to think through what they want to write.

pulmonary disease, are well known ${ }^{5}$ and there are recommendations for risk management in CVD. ${ }^{6}$ There is also an association between these comorbidities and an unhealthy lifestyle in terms of, for example, a sedentary lifestyle, an unhealthy diet, smoking and overconsumption of alcohol. ${ }^{78}$

Alcohol is a psychoactive, dependence-producing substance, which in heavy drinkers causes diseases, and social and economic burden in societies all over the world. Worldwide, $16 \%$ of the population aged 15 or older were reported to be episodic heavy drinkers, though $62 \%$ had not consumed alcohol at all the last 12 months. ${ }^{9}$ Females were more often reported to be abstainers than men. ${ }^{9}$ In Sweden, $17 \%$ (16.5-17.9) of the population aged 16-84 years in 2010 were reported as hazardous drinkers according to Alcohol Use Disorder Investigation Test-Consumption (AUDIT-C) (data from the Swedish National Public Health Survey 2010). AUDIT-C is a validated subset of the consumption items of the full AUDIT. ${ }^{10}$ There are gender differences with the rates of hazardous drinkers among women being 13\% (12.1-13.9) and among 
men 21\% (20.2-22.5). Fifteen per cent (14.2-15.6) were non-drinkers, women $18.0 \%$ (16.5-18.5) and men $12.0 \%$ (11.3-13.2) ${ }^{11}$ In a study of patients with RA in Sweden in $2010,21 \%$ were reported as hazardous drinkers and $11 \%$ non-drinkers ( $14 \%$ women, $4 \%$ men) according to AUDIT-C, which is a higher rate of hazardous drinkers than for the general population in the country. ${ }^{12}$

Strategies aiming to reduce the consumption of alcohol have been introduced worldwide. ${ }^{9}$ The National Board of Health and Welfare in Sweden has published recommendations for the healthcare services to deal with unhealthy lifestyle habits, where a drinking habit is included. These recommendations primarily contain an advisory discussion about lifestyle habits, with the purpose of changing unhealthy behaviour. ${ }^{13}$ There are European recommendations for patient-centred care for RA, which also recommend a discussion focusing on lifestyle habits (physical activity, diet, smoking habits and alcohol) ${ }^{14}$ and which advocate a balanced use of alcohol. ${ }^{14}$

The medical treatment of patients with RA often includes substances that are hepatotoxic. ${ }^{15} 16$ These anti-rheumatic substances can interact with alcohol and enhance the hepatotoxicity. The recommendations of the manufacturer and those of European League Against Rheumatism are that alcohol consumption should be taken into consideration when treating patients with RA with methotrexate (MTX). ${ }^{17}$ Other reasons for considering reduced alcohol consumption are the direct and the indirect effects on the bone tissue, which are related to dose and duration of consumption. A low level of a consumption of one drink per day for women and two for men does not appear to be harmful to the bone tissues, whereas higher consumption may damage these. ${ }^{18}$

Lifestyle discussions regarding alcohol are important to make patients aware of its interactions with medication and second to identify patients with a potential risk behaviour in alcohol use. Studies in the general population show that former heavy drinkers, who are now abstinent, endorsed health concerns most frequently while few referred to medical treatment or doctor's advice as reasons to stop drinking. ${ }^{19}$ In order to be able to help patients with RA to live a healthier lifestyle, regarding their alcohol consumption, knowledge about why people stop drinking alcohol could be useful. Studies of alcohol use in patients with RA are rare and in particular about why they choose to stop drinking alcohol. The aim of the current study was to identify patients with RA who had stopped drinking alcohol and compare them with patients drinking alcohol, and a further aim was to explore reasons for stopping drinking alcohol.

\section{METHODS}

\section{Design}

A sequential explanatory mixed methods design was used $^{20}$ to better understand the complexity of the phenomenon in the study. Both quantitative and qualitative data were collected in a cross-sectional postal questionnaire survey with questions with fixed response alternatives as well as open questions with free-text fields to obtain varied but complementary data. The purpose of the sequential explanatory mixed methods design was to use a qualitative method to inform the analysis of the initial quantitative results. The quantitative results were thus illustrated by qualitative findings to develop a more comprehensive understanding of why patients with RA stopped drinking alcohol.

\section{Patients}

A total of 2800 patients were enrolled in the Better Anti-Rheumatic FarmacOTherapy (BARFOT) study during the period 1992-2006, which is a multicentre longitudinal observational study of patients with early RA (disease duration $<12$ months at inclusion) in Southern Sweden, the details of which have been published. ${ }^{21}$ All patients fulfilled the American College of Rheumatology RA classification criteria from 1987 at inclusion ${ }^{22}$ and had a disease duration of $\leq 1$ year. The patients were assessed in accordance with a structured protocol at inclusion, 3 and 6 months, 1, 2, 5, 8 and 15 years. The patients were treated with disease-modifying antirheumatic drugs (DMARD) according to the recommended treatment strategy in Sweden. ${ }^{21}$ All the patients in the BARFOT study, who were still alive $(n=2102)$, received a self-administered postal questionnaire in the period between March and September 2010 with questions about life style factors (including alcohol questions), health-related quality of life (HRQL), pain and disease-related questions. A total of 1509 patients completed the questions concerning alcohol and were included in the study. Ninety per cent (1364) were ever drinkers, 4\% (59) were non-drinkers and 6\% (86) had stopped drinking alcohol whereof 72 of them also described, in a response to an open question, why they had stopped drinking alcohol. The study was performed in accordance with the Declaration of Helsinki.

\section{The questionnaire}

The questionnaire contained items about activity limitation/disability, assessed by using the Swedish version of the Stanford Health Assessment Questionnaire (HAQ) (0-3 best to worse) ${ }^{23}$ and HRQL assessed by using the (EuroQol five dimensions, EQ5D) (0-1, worse to best) ${ }^{24}$ Numeric Rating Scales $(0-10$, best to worse) were used for assessing general health (patient global assessment; PatGA), fatigue and pain, patient-reported swollen joint counts (SJCs) and tender joint counts (TJCs) (of 28 joints), lifestyle factors such as smoking and alcohol consumption, and medication. The questions assessing alcohol included AUDIT-C, which is a validated subset of the consumption items of the full AUDIT ${ }^{1025}$ and the question 'Have you stopped drinking alcohol?' and an open question 'Why have you stopped drinking alcohol?' The patients were asked to answer the open question in their own words. 


\section{DATA ANALYSIS}

\section{Statistics}

Statistical analyses were performed using SPSS Statistics V.21 software. All significance tests were two tailed and with the significance level set at 0.05 . In testing differences between groups, $\chi^{2}$ was used for proportions and Mann-Whitney $U$ test for continuous variables, due to some of the variables not being normally distributed (Shapiro-Wilks $<0.05$ ). A post hoc power analysis for the separate data in the study showed $62 \%$ power for SJC and TJC, 97\% power for HAQ, 90\% for EQ5D, 99\% for PatGA, 96\% for Visual Analogue Scale (VAS) pain and $80 \%$ for VAS fatigue.

\section{Qualitative content analysis}

A manifest qualitative content analysis was used (what the text says) to analyse the answers from the open question 'Why have you stopped drinking alcohol?' The intention, in the analysis process, was to remain close to the text, preserve contextual meanings and continuously move between the whole and the parts. ${ }^{26}{ }^{27}$ The entire text (unit of analysis) was read through repeatedly to obtain a sense of the whole. Phrases containing information relevant to the aim were identified and extracted, together with surrounding text in order to preserve the context. The meaning units were abstracted and coded, after which they were grouped into five categories that reflected the central message contained in the text. These categories constituted the manifest content. ${ }^{27}$ To increase trustworthiness the authors, who had extensive experience of rheumatology and qualitative methodology, participated in both the research design and data analysis process.

\section{Patient and public involvement}

A patient adviser participated in creating the questionnaire and was involved in the design of the study. This involved reading the questionnaire to ensure that the questions were relevant and easy to understand. The patient adviser was not involved in the recruitment and conduct of the study. The results of the study will be presented at patient associations.

\section{RESULTS}

A total of $1524(72 \%)$ patients answered the questionnaire, 15 of whom did not answer the questions about alcohol and thus 1509 patients were included in the study. The 15 patients, who chose not to answer the questions about alcohol, 14 of whom were women, were between 29 and 89 years in age. The median age for these was 73 years in comparison to 65 years, $\mathrm{p}=0.003$, for those answering the questions about alcohol. There were no statistically significant differences in gender distribution and disease duration between those answering these questions and those who did not. The patients who answered the questions about alcohol were divided in two groups, group $1 \quad(n=86)$, who had stopped drinking alcohol and group $2(n=1423)$, who had not stopped drinking alcohol. There were no statistically significant differences in the rate of hazardous drinkers between the groups according to AUDIT-C (table 1).

Table 1 Descriptives of patients who stopped drinking alcohol (group 1) and those who did not stop drinking alcohol (group 2), median (min-max)

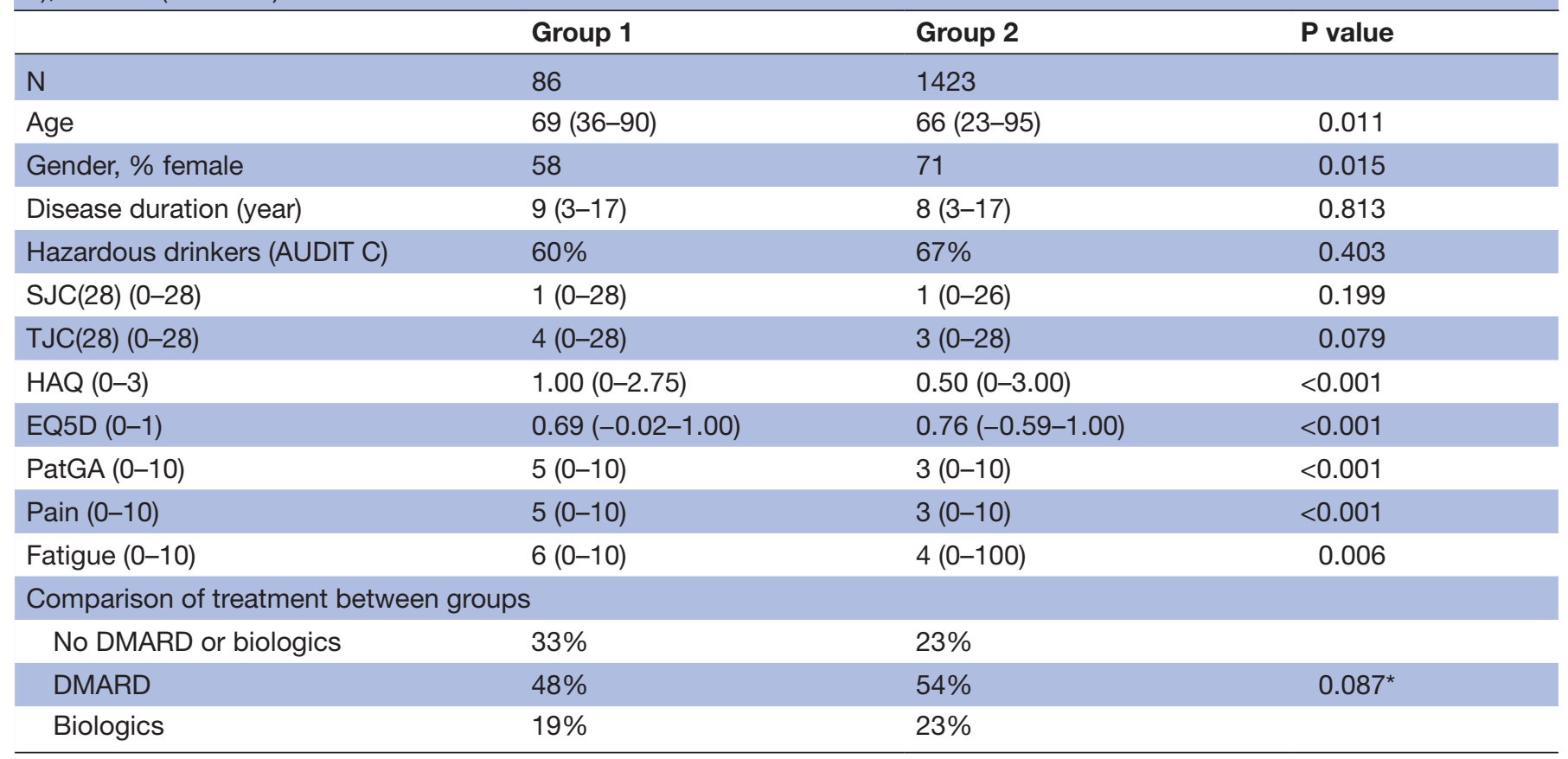

${ }^{*}$ Overall $p$ value calculated by $\chi^{2}$ test for treatment between group 1 and 2 .

AUDIT-C, Alcohol Use Disorder Investigation Test-Consump; DMARD, disease-modifying antireumatic drug; EQ5D, EuroQol five dimensions; $\mathrm{HAQ}$, Health Assessment Questionnaire; PatGA, patient global assessment; SJC(28), swollen joint count (28 joints); TJC(28), tender joint count (28 joints). 


\section{Clinical characteristics}

The patients who had stopped drinking alcohol (group 1) were, at the time for completing the questionnaire, older, had more pain, more fatigue and rated their PatGA at a lower level (table 1). There was a smaller proportion of women in group 1 compared with group $2,58 \%$ vs $71 \%$, $\mathrm{p}=0.015$. Group 1 had more physical limitations based on HAQ, median 1.00 vs 0.50 in group 2, p $<0.001$ and lower HRQL assessed by EQ5D (table 1).

\section{Medical treatment}

There were no statistically significant differences between the groups in terms of treatment (table 1). Approximately half $(52 \%)$ of those treated with DMARD or biologics in group one were treated with only MTX or in combination with another drug, compared with $62 \%$ in group 2 , $\mathrm{p}=0.051$.

\section{Reasons to stop drinking alcohol}

The qualitative content analysis resulted in five categories describing patients' reasons for stopping drinking alcohol: illness and treatment; health and well-being; work and family; faith and solidarity; and dependence and abuse.

\section{IIIness and treatment}

Patients with RA stopped drinking alcohol because of their illness and treatment. The experience of living with a disease such as RA was expressed as an awareness of both the impact of the disease on the body and comorbidity. They also described a fear of a further deterioration in their illness if they were drinking alcohol.

One patient stated:

I stopped drinking alcohol because of the RA illness.

Patients described having a comprehensive and complex drug therapy, both as treatment for RA as well as for comorbidities. They emphasised the information they had received about DMARDs being contraindicated to alcohol. This knowledge was one reason for patients with RA to stop drinking alcohol. Treatment with a combination of several drugs was also a reason for patients to stop drinking alcohol as well as the desire to obtain a good treatment response through adhering to the drug therapy.

Another patient wrote:

Because the information I've read showed that alcohol could have a negative effect on the medicine I take. It was an easy decision so as not to make the illness worse.

\section{Health and well-being}

Patients with RA stopped drinking alcohol because of their health and well-being. They described a conscious choice where they stopped drinking alcohol in order to improve their health. There were patients who did not tolerate alcohol and became ill from drinking it.

One patient declared:

I stopped drinking for the sake of my health.

Patients described their choice to stop drinking alcohol as a lifestyle change. They emphasised the negative effects of alcohol, and that they found no pleasure in drinking alcohol anymore. The patients with RA, who had stopped drinking, expressed no need or motivation for drinking alcohol and experienced increased well-being in life without alcohol.

Another patient wrote:

Thought that it wasn't important, enjoyed life better without alcohol. You can have a lot of fun without alcohol.

\section{Work and family}

Patients with RA stopped drinking alcohol because of their work and family. A work situation that involved driving a car or another motor vehicle was a reason to stop drinking alcohol. Another type of work situation with potential difficulties was that of a salesman, including travelling a lot and attending official dinners, which could result in regular alcohol consumption.

One patient expressed:

I stopped because I got a licence for driving a bus both here and abroad. Drinking alcohol in connection with this is not to be recommended and now I don't have any need for it.

Patients described family life as a reason to stop drinking alcohol. Becoming a parent was described as a turning point in life and a reason to stop drinking. For women, the turning point was a pregnancy. As a parent, there was a desire to be a role model for the children. Patients also expressed that alcohol had affected their family life negatively with trouble within the family, which was one further reason for stopping drinking alcohol.

Another patient wrote:

I got married and started a family and it was completely natural for me to stop drinking alcohol. I have many other interests that I enjoy more, such as nature, hunting and fishing.

\section{Faith and solidarity}

Patients with RA stopped drinking alcohol because of faith and solidarity. There were patients who stated that their faith was a reason for stopping drinking alcohol and they referred to beliefs where refraining from alcohol was advocated, which thus influenced their decision to stop drinking.

One patient stated:

I stopped drinking alcohol because I became a Christian. I noticed that I felt better mentally without alcohol.

Patients also wrote that solidarity was a reason to stop drinking alcohol. They stated that the social acceptance in abstaining completely from alcohol was greater than only taking one glass of alcohol at parties. Solidarity with people, who cannot cope with alcohol, was a reason to stop drinking it.

Another patient stated:

I stopped drinking out of solidarity with those who can't manage to drink alcohol. I've never drunk a great deal so it wasn't a problem for me. I think that it should be just as natural to abstain from alcohol as it is to drink at parties. 


\section{Dependence and abuse}

Patients with RA stopped drinking alcohol because of alcohol dependence and alcohol abuse. There were patients who had become aware of their own increased alcohol consumption, which created a fear of being addicted to alcohol.

One patient described:

Risk for dependence. I stopped this (drinking alcohol) when it was soon to be my 40th. birthday. There had been a tendency towards 'a little too much' of the good things and thus a change was needed.

Patients also described different experiences of alcohol abuse as a reason to stop drinking alcohol. These were experiences of both their own alcohol abuse and that in the family or among their friends contributed to the decision to stop drinking alcohol.

Another patient stated:

I longed to have a drink of spirits when I woke up after partying for several weeks. My grandfather was an alcoholic and it's been a discouraging example.

A total of $86 \%$ of group 1 reported that at least one of the reasons why they stopped drinking was due to their illness and treatment or to improve their health and wellbeing, while only $7 \%$, reported dependence and abuse as their only reason to stop drinking alcohol.

\section{DISCUSSION}

We found that $6 \%$ of the patients with early RA had stopped drinking alcohol in this multicentre longitudinal observational study. Those who had stopped drinking were older, had lower HRQL, more pain and fatigue and worse physical function, but there was no difference in medical treatment between those who had stopped drinking alcohol and those who had not stopped drinking alcohol. This is consistent with research showing that patients, who report not having a regular alcohol consumption, had greater disease severity than patients who consume alcohol regularly. ${ }^{28}$ Green and Polen also found that persons who have stopped drinking are less healthy (physically, mentally and functionally) measured by Short Form Health Survey (SF-36) and had more chronic diseases. ${ }^{29}$ It maybe that patients with less beneficial effects of medical treatment are more motivated to test whether lifestyle changes can reduce their illness symptoms and improve their possibilities for self-influencing their health. This study showed that illness and medical treatment are reasons for patients with RA to stop drinking. This may be due to these patients often being treated with medical substances as MTX, which could have adverse effects when combined with alcohol and a risk of hepatotoxic effects increasing with higher levels of alcohol consumption. ${ }^{15163031}$ On the other hand, there are studies reporting no increased risk of hepatic toxicity associated with alcohol in patients treated with MTX. ${ }^{32-34}$ There are, however, potential interactions between alcohol and other medications and since patients with RA often suffer from comorbidity, knowledge of these interactions could also explain this finding. ${ }^{35}$ This can appear to be ambiguous as research suggests that moderate alcohol consumption is associated with reduced risk of $\mathrm{RA}^{2836-38}$ and reduced disease severity ${ }^{28}$ and better functional status. ${ }^{39}$ There is also an association between alcohol consumption and lower self-reported disease activity and higher HRQL in women. ${ }^{12}$ Hansel $e t$ $a l$ state that a moderate consumption of alcohol is associated with several clinical, biological and social characteristics that benefit health status. ${ }^{40}$ Their research does not demonstrate any significant protective effect of alcohol consumption on the development of RA. ${ }^{41}$ Nor is alcohol associated with the extent of local inflammation in the joints, in spite of the fact that moderate use of alcohol is associated with lower levels of $\mathrm{C}$ reactive protein. ${ }^{42}$ Although there is evidence of a protective effect of alcohol on the development of RA, it is important to be aware of the harmful effects of alcohol. ${ }^{43}$ Fekjaer claims that the harmful effects are stronger than the benefits of alcohol. ${ }^{43}$ Though, there is still a debate about the effect of alcohol consumption on cardiovascular health. ${ }^{44}$

The patients in this study also reported health and wellbeing as reasons to stop drinking alcohol. They wanted to improve health and had an increased well-being after stopping drinking alcohol. Health issues have also been reported in other studies as a reason for this. ${ }^{192945}$ Patients with RA report a reduced use of alcohol after disease onset and drug treatment and they are concerned about drinking alcohol because of the harmful effect. Knowing that alcohol affects health negatively generates feelings of guilt among the patients when drinking alcohol and the patients are motivated to abstain from alcohol in order to achieve good health and improved quality of life. ${ }^{46}$

Most of the patients referred to illness and health as reasons for stopping drinking alcohol, but financial issues linked with being able to work and have an income, new responsibilities linked with becoming a parent and re-evaluating personal habits and being a role model for children as well as religious reasons were all strong motivators to stop drinking, which has been shown in other studies. ${ }^{19} 47$ Some of the patients also wanted to show solidarity with family members, who had been former drinkers and some of them had previous experience of addiction in the family and felt that they had a high consumption of alcohol and were afraid to become addicted themselves.

It is difficult to assess the proportion of patients who stopped drinking alcohol, as there are very few if any studies of this topic. This proportion could be seen to be a little bit low as this group of patients is treated with medicine, which in some cases maybe hepatotoxic. However, Huidekoper et al show that patients with early RA report less alcohol consumption than population controls. ${ }^{48}$ They also found an inverse association between alcohol consumption and being diagnosed with RA. They suggest that alcohol may either protect against having RA or that patients with early RA are less inclined to consume alcohol due to their decreased general well-being. ${ }^{48}$ There are national guidelines for healthcare providers in Sweden to 
deal with unhealthy lifestyle habits that include a drinking habit. ${ }^{13}$ The patients in this study have had regular treatment in the healthcare services and thus should have participated in a discussion about their drinking habits. We have, however, not asked if the patients had reduced their consumption of alcohol after receiving their diagnosis, which could be the case and could to some extent explain the low proportion of patients with RA who had stopped drinking alcohol. The decision to stop drinking in this RA population appears to be a well-informed and conscious choice by the people who want to influence and control their lives. Some have been advised by doctors, relatives or through own experiences to stop and some have done it with the conviction that it is good for their health, family relations and economy. According to Humphreys $e t a l$, there is currently uncertainty about which levels of alcohol consumption are acceptable in the treatment of MTX and thus advice given by healthcare professionals can vary. This can lead to patients avoiding drug treatment with MTX in favour of a potentially safe alcohol consumption. ${ }^{32}$ It is also important for patients with RA to take the influence of alcohol on bone tissue into account. ${ }^{18}$ The effect of alcohol on each individual patient is complex and there are various aspects that have to be considered when healthcare professionals provide advice to patients. Patients' motivation and knowledge about the latest research results are essential when making lifestyle changes and informed decisions, and healthcare providers thus have to remain continuously updated about new research findings in order to provide accurate advice. Finally, in order to succeed in changing lifestyle habits such as reducing alcohol consumption, lifestyle intervention programmes have to be designed with a person-centred approach including knowing the person behind the patient with her/his own will, ${ }^{49}$ emotions, ${ }^{50}$ needs and resources, and recognising the person as an expert on her/his illness and life situation. ${ }^{49}$

A limitation of the study may be that there was no opportunity to ask follow-up questions in order to gain an even greater in-depth understanding, which is possible in interviews. Written responses may, on the other hand, allow patients to think through what they want to write. The fact that the categories covered the data well and that no new category emerged after the 12th written answers from the informants strengthens credibility. The limitation can, however, be partially offset by the fact that there was a large proportion of those who had stopped drinking alcohol who answered the question about why they had done this. The patients in this study were generally relatively old with an established RA disease, which could have affected the outcome of the study. There was a low power in TJC, SJC and VAS fatigue, which is a limitation in these data. Though there was a power between 0.90 and 0.99 for the other analysis.

In conclusion, patients with RA who stopped drinking alcohol have a worse physical function, HRQL, self-perceived health and more pain and fatigue compared with patients with RA drinking alcohol. The reasons for stopping drinking alcohol varied, including medical, physical, mental, social and spiritual aspects, but most of the patients stopped drinking alcohol because of their illness and treatment or to improve their health and wellbeing. Studies of why people stop drinking alcohol are rare and in particular in patients with chronic diseases. Knowledge of why patients stop drinking could be helpful in discussions of lifestyle changes between healthcare providers and patients. It is also evident that more studies are needed and especially focussing on the occurrence of discussions about alcohol within rheumatology care.

Acknowledgements The authors thank the patient adviser, Maria Nylander, for valuable assistance and the other members of the BARFOT Study Group Sofia Ajeganova, Valentina Bala, Björn Svensson, Stefan Bergman, Ann Bremander, Åsa Häggström, Catharina Keller, Ido Leden, Annika Teleman, Jan Theander and Anneli Östenson.

Contributors IL and MA participated in planning the study design and collecting the data. MA performed the statistical analyses and IL performed the qualitative analysis and both drafted the manuscript. Both authors read and approved the final manuscript.

Funding This work had financial support from the research fund of The Regional Board of Southern Sweden, the Swedish Rheumatism Association, The Thelma Zoegas foundation in Helsingborg and the Foundation for Assistance to Disabled People in Skane.

Competing interests None declared.

Patient consent Obtained.

Ethics approval Ethical Review Board in Lund, Sweden (Reg. No. 2009/670).

Provenance and peer review Not commissioned; externally peer reviewed.

Data sharing statement No additional data are available.

Open access This is an open access article distributed in accordance with the Creative Commons Attribution Non Commercial (CC BY-NC 4.0) license, which permits others to distribute, remix, adapt, build upon this work non-commercially, and license their derivative works on different terms, provided the original work is properly cited, appropriate credit is given, any changes made indicated, and the use is non-commercial. See: http://creativecommons.org/licenses/by-nc/4.0/.

\section{REFERENCES}

1. Scott DL, Wolfe F, Huizinga TW. Rheumatoid arthritis. Lancet 2010;376:1094-108.

2. Englund M, Jöud A, Geborek P, et al. Prevalence and incidence of rheumatoid arthritis in southern Sweden 2008 and their relation to prescribed biologics. Rheumatology 2010;49:1563-9.

3. Eriksson JK, Neovius M, Ernestam S, et al. Incidence of rheumatoid arthritis in Sweden: a nationwide population-based assessment of incidence, its determinants, and treatment penetration. Arthritis Care Res 2013;65:870-8.

4. Uhlig T, Moe RH, Kvien TK. The burden of disease in rheumatoid arthritis. Pharmacoeconomics 2014;32:841-51.

5. Dougados M, Soubrier M, Antunez A, et al. Prevalence of comorbidities in rheumatoid arthritis and evaluation of their monitoring: results of an international, cross-sectional study (COMORA). Ann Rheum Dis 2014;73:62-8.

6. Agca R, Heslinga SC, Rollefstad S, et al. EULAR recommendations for cardiovascular disease risk management in patients with rheumatoid arthritis and other forms of inflammatory joint disorders: 2015/2016 update. Ann Rheum Dis 2017;76:17-28.

7. Beaglehole R, Bonita R, Alleyne G, et al. UN High-Level Meeting on Non-Communicable Diseases: addressing four questions. Lancet 2011;378:449-55.

8. Michaud K, Wolfe F. Comorbidities in rheumatoid arthritis. Best Pract Res Clin Rheumatol 2007;21:885-906.

9. World Health Organisation. Global status report on alcohol and health. 2014

10. Bush K, Kivlahan DR, McDonell MB, et al. The AUDIT alcohol consumption questions (AUDIT-C): an effective brief screening test for problem drinking. Ambulatory Care Quality Improvement Project 
(ACQUIP). Alcohol Use Disorders Identification Test. Arch Intern Med 1998;158:1789-95.

11. Swedish National public health survey. Health on equal terms. 2010.

12. Bergman S, Symeonidou S, Andersson ML, et al. Alcohol consumption is associated with lower self-reported disease activity and better health-related quality of life in female rheumatoid arthritis patients in Sweden: data from BARFOT, a multicenter study on early RA. BMC Musculoskelet Disord 2013;14:218.

13. Swedish Social Board. National guidelines for disease prevention methods. 2017.

14. Stoffer MA, Smolen JS, Woolf A, et al. Development of patientcentred standards of care for rheumatoid arthritis in Europe: the eumusc.net project. Ann Rheum Dis 2014;73:902-5.

15. Kremer JM, Alarcón GS, Lightfoot RW, et al. Methotrexate for rheumatoid arthritis. Suggested guidelines for monitoring liver toxicity. American College of Rheumatology. Arthritis Rheum 1994;37:316-28.

16. Kremer JM, Furst DE, Weinblatt ME, et al. Significant changes in serum AST across hepatic histological biopsy grades: prospective analysis of 3 cohorts receiving methotrexate therapy for rheumatoid arthritis. J Rheumatol 1996;23:459-61.

17. Smolen JS, Landewé R, Bijlsma J, et al. EULAR recommendations for the management of rheumatoid arthritis with synthetic and biological disease-modifying antirheumatic drugs: 2016 update. Ann Rheum Dis 2017;76:960-77.

18. Maurel DB, Boisseau N, Benhamou CL, et al. Alcohol and bone: review of dose effects and mechanisms. Osteoporos Int 2012;23:1-16.

19. Cunningham JA, Koski-Jännes A, Toneatto T. Why do people stop their drug use? Results from a general population sample. Contemp Drug Probl 1999;26:695-710.

20. Creswell JW, Clark VLP. Designing and conducting mixed methods research. Thousand Oaks: SAGE Publications, 2011.

21. Andersson ML, Forslind K, Hafström I. Comparing five year out-come in two cohorts of patients with early rheumatoid arthritis - A BARFOT Study. Open Rheumatol J 2015;9:8-15.

22. Arnett FC, Edworthy SM, Bloch DA, et al. The American Rheumatism association 1987 revised criteria for the classification of rheumatoid arthritis. Arthritis Rheum 1988;31:315-24.

23. Ekdahl C, Eberhardt $\mathrm{K}$, Andersson $\mathrm{SI}$, et al. Assessing disability in patients with rheumatoid arthritis. use of a swedish version of the stanford health assessment questionnaire. Scand J Rheumatol 1988;17:263-71.

24. Hurst NP, Kind P, Ruta D, et al. Measuring health-related quality of life in rheumatoid arthritis: validity, responsiveness and reliability of EuroQol (EQ-5D). Br J Rheumatol 1997;36:551-9.

25. Fleming MF, Barry KL, MacDonald R. The alcohol use disorders identification test (AUDIT) in a college sample. Int $J$ Addict 1991;26:1173-85.

26. Graneheim UH, Lindgren BM, Lundman B. Methodological challenges in qualitative content analysis: a discussion paper. Nurse Educ Today 2017:56:29-34.

27. Graneheim UH, Lundman B. Qualitative content analysis in nursing research: concepts, procedures and measures to achieve trustworthiness. Nurse Educ Today 2004;24:105-12.

28. Maxwell JR, Gowers IR, Moore DJ, et al. Alcohol consumption is inversely associated with risk and severity of rheumatoid arthritis. Rheumatology 2010;49:2140-6.

29. Green CA, Polen MR. The health and health behaviors of people who do not drink alcohol. Am J Prev Med 2001;21:298-305.

30. Kremer JM, Weinblatt ME. Quantifying the hepatotoxic risk of alcohol consumption in patients with rheumatoid arthritis taking methotrexate. Ann Rheum Dis 2018;77:e4.
31. Price S, James C, Deighton C. Methotrexate use and alcohol. Clin Exp Rheumatol 2010;5:S114-6.

32. Humphreys JH, Warner A, Costello R, et al. Quantifying the hepatotoxic risk of alcohol consumption in patients with rheumatoid arthritis taking methotrexate. Ann Rheum Dis 2017;76:1509-14.

33. Rajakulendran S, Gadsby K, Deighton C. Rheumatoid arthritis, alcohol, leflunomide and methotrexate. Can changes to the BSR guidelines for leflunomide and methotrexate on alcohol consumption be justified? Musculoskeletal Care 2008;6:233-46.

34. Tilling L, Townsend S, David J. Methotrexate and hepatic toxicity in rheumatoid arthritis and psoriatic arthritis. Clin Drug Investig 2006;26:55-62.

35. Chan LN, Anderson GD. Pharmacokinetic and pharmacodynamic drug interactions with ethanol (alcohol). Clin Pharmacokinet 2014:53:1115-36.

36. Jin Z, Xiang C, Cai Q, et al. Alcohol consumption as a preventive factor for developing rheumatoid arthritis: a dose-response metaanalysis of prospective studies. Ann Rheum Dis 2014;73:1962-7.

37. Lu B, Solomon DH, Costenbader KH, et al. Alcohol consumption and risk of incident rheumatoid arthritis in women: a prospective study. Arthritis Rheumatol 2014;66:1998-2005.

38. Scott IC, Tan R, Stahl D, et al. The protective effect of alcohol on developing rheumatoid arthritis: a systematic review and metaanalysis. Rheumatology 2013;52:856-67.

39. Lu B, Rho YH, Cui J, et al. Associations of smoking and alcohol consumption with disease activity and functional status in rheumatoid arthritis. J Rheumatol 2014;41:24-30.

40. Hansel B, Thomas F, Pannier B, et al. Relationship between alcohol intake, health and social status and cardiovascular risk factors in the Urban Paris-lle-de-France Cohort: is the cardioprotective action of alcohol a myth? Eur J Clin Nutr 2010;64:561-8.

41. Sundström B, Johansson I, Rantapää-Dahlqvist S. Diet and alcohol as risk factors for rheumatoid arthritis: a nested case-control study. Rheumatol Int 2015;35:533-9.

42. Mangnus L, van Steenbergen HW, Nieuwenhuis WP, et al. Moderate use of alcohol is associated with lower levels of $C$ reactive protein but not with less severe joint inflammation: a cross-sectional study in early RA and healthy volunteers. RMD Open 2018;4:e000577.

43. Fekjaer $\mathrm{HO}$. Alcohol-a universal preventive agent? A critical analysis. Addiction 2013;108:2051-7.

44. Goel S, Sharma A, Garg A. Effect of alcohol consumption on cardiovascular health. Curr Cardiol Rep 2018;20:19.

45. Cunningham JA, Sobell LC, Sobell MB, et al. Resolution from alcohol problems with and without treatment: reasons for change. J Subst Abuse 1995; 7:365-72.

46. Malm K, Bremander A, Arvidsson B, et al. The influence of lifestyle habits on quality of life in patients with established rheumatoid arthritis-A constant balancing between ideality and reality. Int J Qual Stud Health Well-being 2016;11:30534.

47. George LK, Larson DB, Koenig HG, et al. Spirituality and health: what we know, what we need to know. J Soc Clin Psychol 2000;19:102-16.

48. Huidekoper AL, van der Woude D, Knevel R, et al. Patients with early arthritis consume less alcohol than controls, regardless of the type of arthritis. Rheumatology 2013;52:1701-7.

49. Lidin M, Ekblom-Bak E, Rydell Karlsson M, et al. Long-term effects of a Swedish lifestyle intervention programme on lifestyle habits and quality of life in people with increased cardiovascular risk. Scand J Public Health 2018;46:613-22.

50. Ashton K, Bellis MA, Davies AR, et al. Do emotions related to alcohol consumption differ by alcohol type? An international crosssectional survey of emotions associated with alcohol consumption and influence on drink choice in different settings. BMJ Open 2017;7:e016089. 